\title{
mTOR Signaling Combined with Cancer Stem Cell Markers as a Survival Predictor in Stage II Colorectal Cancer
}

\author{
Ji Young Chang ${ }^{1}$, Jae Hyun Kim¹, Joyeon Kang ${ }^{1,4}$, Yehyun Park ${ }^{1}$, Soo Jung Park ${ }^{1}$, \\ Jae Hee Cheon ${ }^{1}$, Won Ho Kim ${ }^{1}$, Hoguen Kim, ${ }^{2,4}$, Jae Jun Park ${ }^{1,3}$, and Tae Il Kim ${ }^{1,3,4}$ \\ Departments of ${ }^{1}$ Internal Medicine and Institute of Gastroenterology, and ${ }^{2}$ Pathology, Yonsei University College of Medicine, Seoul; \\ ${ }^{3}$ Yonsei Cancer Prevention Center, Seoul; \\ ${ }^{4}$ Brain Korea 21 PLUS Project for Medical Sciences, Yonsei University College of Medicine, Seoul, Korea.
}

Purpose: Wnt and mammalian target of rapamycin (mTOR) are major molecular signaling pathways associated with the development and progression of tumor, as well as the maintenance and proliferation of cancer stem cells (CSCs), in colorectal cancer (CRC). Identifying patients at risk of poor prognosis is important to determining whether to add adjuvant treatment in stage II CRC and thus improve survival. In the present study, we evaluated the prognostic value of Wnt, mTOR, and CSC markers as survival predictors in stage II CRC.

Materials and Methods: We identified 148 cases of stage II CRC and acquired their tumor tissue. Tissue microarrays for immunohistochemical staining were constructed, and the expressions of CD166, CD44, EphB2, $\beta$-catenin, pS6 were evaluated using immunohistochemical staining.

Results: The expressions of CD166 ( $p=0.045)$ and pS6 ( $p=0.045)$ and co-expression of pS6/CD166 ( $p=0.005), \mathrm{pS6} / \mathrm{CD} 44(p=0.042)$, and pS6/CD44/CD166 ( $p=0.013$ ) were negatively correlated with cancer-specific survival. Cox proportional hazard analysis showed the combination of CD166/pS6 [hazard ratio, 9.42; 95\% confidence interval, $2.36-37.59 ; p=0.002$ ] to be the most significant predictor related with decreased cancer-specific survival. In addition, co-expression of CD44/CD166 ( $p=0.017), \mathrm{CD166/}$ $\beta$-catenin ( $p=0.036), \mathrm{CD} 44 / \beta$-catenin $(p=0.001)$, and $\mathrm{CD} 44 / \mathrm{CD} 166 / \beta$-catenin $(p=0.001)$ were significant factors associated with liver metastasis.

Conclusion: Specific combinations of CSC markers and $\beta$-catenin/mTOR signaling could be a significant predictor of poor survival in stage II CRC.

Key Words: Neoplastic stem cell, carcinogenesis, colorectal cancer, prognosis, survival

Received: January 17, 2020 Revised: April 26, 2020

Accepted: May 18, 2020

Co-corresponding authors: Jae Jun Park, MD, PhD, Department of Internal Medicine, Institute of Gastroenterology, Yonsei University College of Medicine, 50-1 Yonsei-ro, Seodaemun-gu, Seoul 03722, Korea.

Tel: 82-2-2228-4371, Fax: 82-2-393-6884, E-mail: jaejpark@yuhs.ac and

Tae II Kim, MD, PhD, Department of Internal Medicine, Institute of Gastroenterology, Yonsei University College of Medicine, 50-1 Yonsei-ro, Seodaemun-gu, Seoul 03722, Korea.

Tel: 82-2-2228-1965, Fax: 82-2-393-6884, E-mail: taeilkim@yuhs.ac

-The authors have no potential conflicts of interest to disclose.

(c) Copyright: Yonsei University College of Medicine 2020

This is an Open Access article distributed under the terms of the Creative Commons Attribution Non-Commercial License (https://creativecommons.org/licenses/ by-nc/4.0) which permits unrestricted non-commercial use, distribution, and reproduction in any medium, provided the original work is properly cited.

\section{INTRODUCTION}

The characteristic diversity of colorectal cancer (CRC) is thought to be due to its unique genetic and/or epigenetic oncogenesis. ${ }^{1}$ Although cancer stem cells (CSCs) constitute only a minor tumor population, they have a major role in tumor maintenance and recurrence, ${ }^{2,3}$ as well as in initiation of organized carcinogenesis. In the last two decades, several markers, including CD133, CD44, CD166, CD24, ALDH1, LGR5, and $\mathrm{EPhB} 2$, have been identified as CSC markers in CRC. ${ }^{1}$ Based on these markers, numerous studies have been performed to evaluate the clinical relevance of these putative CSCs in CRC survival, ${ }^{4,5}$ progression, ${ }^{3,6,7}$ and therapeutic feasibility. ${ }^{8,9}$ 
Signaling pathways that can induce Wnt/ $\beta$-catenin and mammalian target of rapamycin (mTOR) play fundamental roles in early carcinogenesis, CSC maintenance, and CRC progression. Under normal circumstances, Wnt signaling regulates the proliferation and differentiation of stem cells, as well as embryonic development and tissue homeostasis, by controlling amounts of $\beta$-catenin. ${ }^{10}$ In cancer development, Wnt $/ \beta$-catenin signaling is activated by either a mutation that results in loss of function of the adenomatosis polyposis coli gene or a $\beta$-catenin mutation, which subsequently leads to accumulation of $\beta$-catenin and cancer development. ${ }^{11-13}$ In addition, phosphatidylinositol-3-kinase (PI3K)/Akt/mTOR signaling is another key molecular signal for sustaining tumor growth and metastasis. ${ }^{14}$ mTOR is activated by its upstream effector, Akt, and regulates cell growth and proliferation by mediating multiple signals, including growth factors, nutrients, hormones, and energy or stress status. ${ }^{14-16}$ The ribosomal protein $\mathrm{pS6}$ is a marker of active mTOR signaling and plays a role in cell survival, proliferation, angiogenesis, and protein synthesis. ${ }^{17}$ Thus, Wnt and mTOR inhibitors have been researched as potential targets for anti-cancer therapy. ${ }^{16}$

With respect to clinical aspects of CRC treatment, identification of poor prognostic molecular markers in stage II CRC is an important issue for improving survival, helping clinicians discern whether to add more aggressive adjuvant chemotherapy. However, the clinical relevance of several putative markers of CSCs or molecular signals has been evaluated in only a few studies, and there has been no comprehensive analysis of the combined expression of these markers as prognostic factors in stage II CRC. Thus, in the present study, the expression patterns of CSC markers (CD166, CD44, EPhB2) and major target signal markers ( $\beta$-catenin, pS6) using tissue microarray (TMA) were evaluated, and the association of their combined expression with long-term survival outcomes in stage II CRC patients was assessed.

\section{MATERIALS AND METHODS}

\section{Study subjects and data collection}

We identified all cases of resected CRCs at Severance Hospital, Yonsei University College of Medicine, Seoul, Korea between December 2002 and July 2006. Patients diagnosed with stage II colorectal adenocarcinoma without previous treatment were included. Patients who fulfilled any of the following criteria were excluded: 1) history of other malignant disease; 2) other types of CRC, including squamous cell, neuroendocrine, or spindle cell carcinoma; 3) familiar polyposis syndrome, including familial adenomatous polyposis, or Lynch syndrome; or 4) inadequate medical information or any error in immunohistochemical staining (IHCS) of the five markers. The Institutional Review Board of Severance Hospital approved this study (IRB number; 4-2018-1174).

\section{TMA construction and IHCS}

TMAs were constructed after review of hematoxylin and eosin stained slides by a pathologist for selection of representative tumor areas. Two cores from the primary cancer and one core from normal tissue $2 \mathrm{~mm}$ in diameter were punched from the paraffin blocks for tissue array blocks. Each tissue array block contained 48 cores consisting of 16 cases.

TMA paraffin blocks were serially cut to a thickness of $4 \mu \mathrm{m}$. After deparaffinization and rehydration, antigen retrieval was performed using citrate buffer (10 mM, pH 6.0). IHCS using anti-CD166, anti-CD44, $\beta$-catenin (Santa Cruz, Delaware, CA, USA), anti-EphB2, and anti-pS6 antibodies (Cell Signaling Technology, Danvers, MA, USA) was performed on the TMA slides. After 30 min of incubation with a Vectastain ABC kit (Vector Labs, Burlingame, CA, USA), sections were visualized using diaminobenzidine solution. TMA sections were counterstained with hematoxylin for $1 \mathrm{~min}$, dehydrated in $70 \%, 80 \%, 90 \%$, and $100 \%$ ethanol, cleared in xylene, and mounted in Balsam. A negative control of IHCS was made by applying a secondary antibody without a primary antibody.

\section{Scoring of CD166, CD44, EphB2, $\beta$-catenin, and pS6 expression}

CD166, CD44, and EphB2 were evaluated as CSC markers, ${ }^{1}$ nuclear $\beta$-catenin as a canonical Wnt $/ \beta$-catenin signal ${ }^{10}$ and pS6 as a marker of active mTOR signaling. ${ }^{18}$ IHCS of each marker was evaluated by two trained researchers (Ji Young Chang and Jae Hyun Kim). The IHCS of CD44, EphB2, and nuclear $\beta$-catenin was evaluated based on the staining intensity of positive tumor cells (Supplementary Fig. 1, only online). Staining intensity was scored using the following 4-point scale: 0 for negative staining; 1 for weak, light yellow staining; 2 for moderate, yellowish brown staining; and 3 for strong, brown staining (Supplementary Fig. 1, only online)..$^{19}$ The expressions of CD166 and pS6 were evaluated as positive or negative, because IHCS for CD166 and pS6 is relatively weaker than that for other markers (Supplementary Fig. 1, only online). ${ }^{5}$

\section{Data collection and assessment}

Clinical and pathologic data were collected by reviewing medical records. Tumor staging was evaluated based on the seventh edition of the American Joint Committee on Cancer/ Union International Control Center (AJCC/UICC) TNM staging manual. Histological classification of CRC was evaluated based on the World Health Organization classification. ${ }^{20}$ Clinical high-risk features for poor prognosis included poorly differentiated histology, presence of lymphovascular invasion, presence of perineural invasion, less than 12 lymph nodes reported, bowel obstruction, localized perforation, or positive margins. ${ }^{21}$ Overall survival was defined as survival from the time of treatment to death due to any cause, whereas cancerspecific survival was defined as survival from the time of treatment to colon cancer-related death. ${ }^{22}$ 


\section{Statistical analyses}

All statistical analyses were conducted using SPSS version 22.0 (IBM Corp., Armonk, NY, USA). Student's t-tests were used for continuous variables, and the chi-square test, Fisher's exact test, or linear-by-linear association was used for categorical variables. The Kaplan-Meier method and the log-rank test were performed to identify cumulative survival rates based on marker expression. Furthermore, Cox proportional hazard analysis was performed to identify independent predictive factors for longterm survival outcomes. $p$ values $<0.05$ were considered statistically significant.

\section{RESULTS}

\section{Baseline patient characteristics}

A total of 190 patients were found to have stage II CRC and underwent surgery. Of these, 148 patients who showed adequate IHCS quality and good medical compliance were included in this study. A detailed flowchart of study subjects is shown in Fig. 1. Baseline characteristics of the study subjects are shown in Table 1. The median age of the study population was 62.0 years [interquartile range (IQR), 54.0-68.0], and $62.8 \%$ were male. Based on the AJCC/UICC staging system, 146 (98.6\%) cases were T3, and the other 2 cases $(1.4 \%)$ were T4. The median tumor size was $5.0 \mathrm{~cm}$ (IQR, 4.0-6.4). High-risk features were found in 72 patients [poorly differentiated histology, 5 (3.4\%); presence of lymphovascular invasion, $40(27.0 \%)$; presence of perineural invasion, 14 (9.5\%); less than 12 lymph nodes reported, $10(6.8 \%)$; bowel obstruction, $1(0.7 \%)$; positive margins, 2 (1.4\%); respectively]. In treatment with adjuvant chemotherapy, we found that a relatively high portion of patients had received chemotherapy, even in patients with stage II CRC without high risk features. A 5-fluorouracil (5-FU)/leucovorin
(LV) regimen was most frequently prescribed $(125,93.3 \%)$, followed by capecitabine $(6,4.5 \%)$ and FOLFOX (5-FU/LV/oxaliplatin) regimens $(3,2.2 \%)$. The median follow-up duration was

Table 1. Baseline Characteristics of the Study Subjects

\begin{tabular}{lc}
\hline \multicolumn{1}{c}{ Characteristics } & $\mathbf{n = 1 4 8}$ \\
\hline Age at diagnosis (yr) & $62.0(54.0-68.0)$ \\
Male sex & $93(62.8)$ \\
\hline Family history of colorectal cancer & \\
\hline No & $141(95.3)$ \\
\hline Yes & $7(4.7)$ \\
Preoperative CEA (ng/mL) & \\
\hline$<5$ & $103(69.6)$ \\
\hline$\geq 5$ & $45(30.4)$ \\
\hline Tumor size (cm) & $5.0(4.0-6.4)$ \\
\hline Location & \\
\hline Ascending & $28(18.9)$ \\
\hline Transverse & $5(3.4)$ \\
\hline Descending & $50(33.8)$ \\
\hline Rectum & $65(43.9)$ \\
\hline T stage & $146(98.6)$ \\
\hline T3 & $2(1.4)$ \\
\hline T4 & \\
\hline Histology & $23(15.5)$ \\
\hline Well-differentiated & $120(81.1)$ \\
\hline Moderate-differentiated & $5(3.4)$ \\
\hline Undifferentiated* & $134(90.5)$ \\
\hline High-risk features & \\
\hline IQRemotherapy interquartile range; CEA, carcinoembryonic antigen. & \\
Data are presented as number (\%) or median (IOR). & \\
*Undifferentiated histology included poorly differentiated, mucinous adeno- \\
carcinoma, and signet-ring cancer subtype.
\end{tabular}

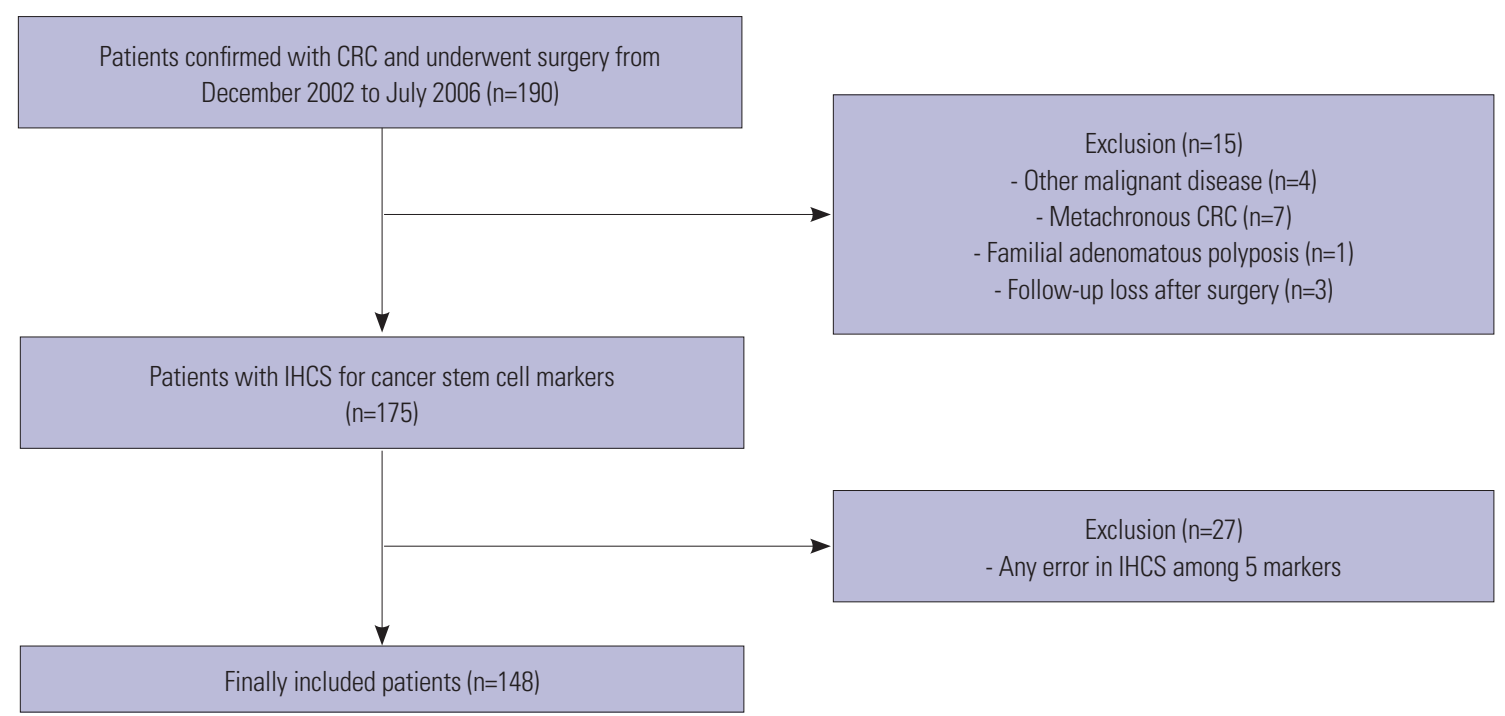

Fig. 1. Flow chart of the enrolled study subjects. CRC, colorectal cancer; IHCS, immunohistochemical staining. 
12.2 years (IQR, 11.0-13.4).

\section{IHCS staining and survival analysis}

The proportions of positive expression of CD166, CD44, EphB2, $\beta$-catenin, and pS6 were $61.5 \%$ (91 cases), $51.4 \%$ (76 cases), $14.9 \%$ (22 cases), $60.8 \%$ (90 cases), and $23.6 \%$ (35 cases), respectively. Within the median follow-up period, 30 patients died, and 11 deaths were associated with CRC progression.

Using Kaplan-Meier survival curves, the association between overall survival rate and the expression of each individual marker or combinations thereof were analyzed. pS6 expression ( $p=0.004)$ and co-expression of pS6/CD166 ( $p=0.003)$, $\mathrm{pS6} / \mathrm{CD} 44$ ( $p=0.002), \mathrm{pS6} / \mathrm{CD} 166 / \mathrm{CD} 44$ ( $p=0.008)$, and pS6/ CD166/ $\beta$-catenin $(p=0.040)$ were significantly correlated with low survival (Supplementary Fig. 2, only online). Cox multivariate adjusted analysis for overall survival showed clinical factors of age and chemotherapy and IHCS markers pS6 ( $p=$ 0.002), pS6/CD44 ( $p<0.001), \mathrm{pS6} / \mathrm{CD} 166(p<0.001), \mathrm{pS} 6 /$ CD166/CD44 ( $p=0.001)$, and pS6/CD166/ $\beta$-catenin $(p=0.008)$ were significant. Detailed results from the univariate and multivariate analyses for overall survival are provided in Supplementary Tables 1 and 2 (only online).

As for cancer-specific survival, Kaplan-Meier analysis showed CD166 ( $p=0.045), \mathrm{pS6}$ ( $p=0.045)$, and co-expression of pS6/
CD166 ( $p=0.005), \mathrm{pS6} / \mathrm{CD} 44$ ( $p=0.042)$, and pS6/CD166/CD44 $(p=0.013)$ were significant factors (Fig. 2). In univariate analysis, preoperative CEA $>5 \mathrm{ng} / \mathrm{mL}(p=0.006)$ and presence of high-risk features $(p=0.041)$ were associated with decreased cancer-specific survival, whereas chemotherapy ( $p=0.046)$ was correlated with improved cancer-specific survival. In addition, the co-expression of pS6/CD166 ( $p=0.010)$, and pS6/CD166/ CD44 ( $p=0.022$ ) was significantly associated with poor cancerspecific survival (Table 2). After adjusting for clinically relevant factors, the IHCS markers pS6 ( $p=0.018)$, pS6/CD166 ( $p=$ 0.002), $\mathrm{pS6} / \mathrm{CD} 44$ ( $p=0.015), \mathrm{CD} 166 / \mathrm{CD} 44$ ( $p=0.034), \mathrm{pS} 6 /$ CD166/ $\beta$-catenin ( $p=0.035)$, and pS6/CD166/CD44 ( $p=0.005)$ were negatively correlated with cancer-specific survival in multivariate Cox analysis (Table 3). The expression of pS6/CD166 [hazard ratio (HR), 9.42; 95\% confidence interval (CI), 2.3637.59; $p=0.002]$ was identified as the most influential factor along with chemotherapy (HR, 0.14; 95\% CI, 0.03-0.71; $p=0.017$ ) among clinically relevant factors. Detailed multivariate results for IHCS markers and their combinations are shown in Supplementary Table 3 (only online).

With respect to recurrence, there were 20 recurrences (13.5\%) among 148 patients, and the estimated 3- and 5-year recurrence free survival rates were $92.8 \%$ and $86.5 \%$, respectively. However, there was no significant association between specif-
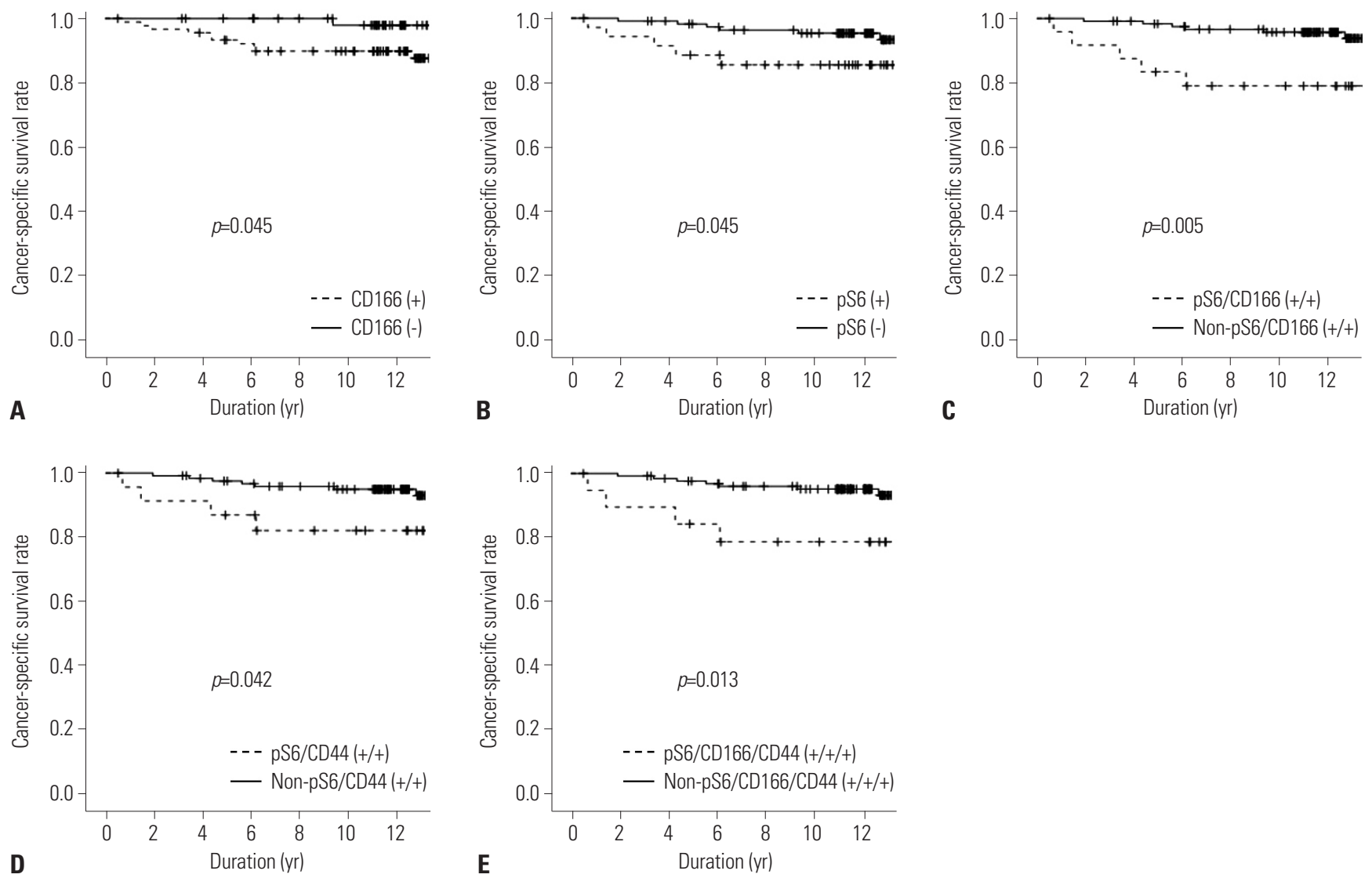

Fig. 2. Kaplan-Meier curves showing cumulative cancer-specific survival rates in stage II colorectal cancer based on the expression of CD166, CD44, and pS6 and combinations thereof: (A) CD166, (B) pS6, (C) pS6/CD166, (D) pS6/CD44, and (E) pS6/CD166/CD44. 
Table 2. Univariate Analysis for Clinicopathologic Factors and Markers of Immunohistochemical Stains Related to Cancer-Specific Survival in Stage II Colorectal Cancer

\begin{tabular}{|c|c|c|c|}
\hline & HR & $95 \% \mathrm{Cl}$ & $p$ value \\
\hline Sex (female vs. male) & 1.42 & $0.13-4.66$ & 0.562 \\
\hline Age (>60 vs. $\leq 60$ yr) & 3.38 & $0.73-15.65$ & 0.120 \\
\hline CEA (>5 vs. $\leq 5 \mathrm{ng} / \mathrm{mL}$ ) & 6.37 & $1.69-24.02$ & 0.006 \\
\hline Size (>5 vs. $\leq 5 \mathrm{~cm})$ & 1.82 & $0.48-6.88$ & 0.375 \\
\hline $\begin{array}{l}\text { Histologic differentiation (well/moderate } \\
\text { vs. undifferentiated/poorly) }\end{array}$ & 0.05 & $0.0-84100.0$ & 0.677 \\
\hline Chemotherapy (yes vs. no) & 0.26 & $0.07-0.98$ & 0.046 \\
\hline High-risk feature* (yes vs. no) & 4.95 & $1.07-22.94$ & 0.041 \\
\hline \multicolumn{4}{|l|}{ Marker expression } \\
\hline CD166 (+) vs. CD166 (-) & 6.28 & $0.80-48.13$ & 0.080 \\
\hline CD44 (+) vs. CD44 (-) & 1.59 & $0.46-5.48$ & 0.460 \\
\hline EphB2 (+) vs. EphB2 (-) & 0.04 & $0.0-52.43$ & 0.377 \\
\hline$\beta$-catenin (+) vs. $\beta$-catenin (-) & 0.74 & $0.23-2.42$ & 0.618 \\
\hline pS6 (+) vs. pS6 (-) & 2.93 & $0.89-9.61$ & 0.076 \\
\hline CD166/CD44 (+/+) vs. others & 3.14 & $0.92-10.77$ & 0.069 \\
\hline pS6/CD166 (+/+) vs. others & 4.76 & $1.45-15.61$ & 0.010 \\
\hline pS6/CD44 (+/+) vs. others & 3.32 & $0.97-11.38$ & 0.056 \\
\hline pS6/CD166/CD44 (+/+/+) vs. others & 4.22 & $1.23-14.44$ & 0.022 \\
\hline
\end{tabular}

$\mathrm{HR}$, hazard ratio; $\mathrm{Cl}$, confidence interval; $\mathrm{CEA}$, carcinoembryonic antigen. *High-risk features include poorly differentiated histology, presence of lymphovascular invasion, presence of perineural invasion, bowel obstruction, localized perforation, or positive margins.

Table 3. Cox Multivariate Adjusted Analysis* for Markers of Immunohistochemical Stains Related to Cancer-Specific Survival in Stage II Colorectal Cancer

\begin{tabular}{lccc}
\hline & HR & 95\% Cl & $\boldsymbol{p}$ value \\
\hline pS6 (+) vs. pS6 (-) & 4.94 & $1.32-18.50$ & 0.018 \\
pS6/CD166 (+/+) vs. others & 9.42 & $2.36-37.59$ & 0.002 \\
pS6/CD44 (+/+) vs. others & 5.36 & $1.38-20.81$ & 0.015 \\
CD166/CD44 (+/+) vs. others & 4.39 & $1.12-17.19$ & 0.034 \\
pS6/CD166/ $/$-catenin (+/+/+) vs. others & 7.05 & $1.15-43.18$ & 0.035 \\
pS6/CD166/CD44 (+/+/+) vs. others & 7.11 & $1.82-27.69$ & 0.005 \\
\hline
\end{tabular}

$\mathrm{HR}$, hazard ratio; $\mathrm{Cl}$, confidence interval; $\mathrm{CEA}$, carcinoembryonic antigen.

*Adjusted for sex, age, CEA, tumor size, chemotherapy, high-risk features.

ic expression of CSC markers and/or $\beta$-catenin/mTOR signals and recurrence of CRC.

In subgroup analysis, the influence of specific expression of CSC markers and/or $\beta$-catenin/mTOR signals on recurrence with liver metastasis was analyzed. Univariate analysis showed co-expression of CD44/CD166 ( $p=0.017), \mathrm{CD} 166 / \beta$-catenin $(p=$ $0.036), \mathrm{CD} 44 / \beta$-catenin ( $p=0.001)$, and CD44/CD166/ $\beta$-catenin ( $p=0.001)$ to be significant factors associated with liver metastasis (Supplementary Fig. 3, only online). Multivariate analysis was not performed due to the small number of events.

\section{DISCUSSION}

In this study, combined expression of specific CSC markers (CD166, CD44) and an mTOR signaling marker (pS6) were independently associated with cancer-specific survival, as well as overall survival, in stage II CRC. Among the combinations of these markers, co-expression of CD166 and pS6 was most negatively correlated with cancer-specific survival. However, previously known high-risk features did not significantly affect cancer-specific survival, whereas chemotherapy improved cancer-specific survival. Specific combinations of the expression of CSC markers (CD166, CD44) and Wnt signal marker ( $\beta$-catenin) were found to have a significant role in liver metastasis.

Stage II CRC has heterogeneous characteristics regarding curability after surgery ${ }^{21}$ Although stage II CRC has not spread to a lymph node, the risk of micrometastatic disease that could develop into macrometastatic disease is present. Thus, the American Society of Clinical Oncology ${ }^{23}$ and the European Society of Medical Oncology ${ }^{24}$ have recommended adjuvant chemotherapy in selected patients with clinical high-risk features. However, opinions differ regarding the effectiveness of adjuvant chemotherapy based on known high-risk features. O'Connor, et al. ${ }^{25}$ reported that adjuvant chemotherapy did not improve overall survival in patients with (HR, 1.03; 95\% CI, 0.94-1.13) or without poor prognostic features (HR, 1.02; 95\% CI, 0.84-1.25) in stage II CRC. Thus, to identify other molecular predictors of the clinical impact of adjuvant chemotherapy, the assessment of mismatch repair deficient or microsatellite instability (MSI) has emerged. MSI is caused by abnormality in the DNA mismatch repair pathway. In stage II CRC, patients with MSI-high have been shown to be associated with better overall survival (HR, 0.31; 95\% CI, 0.14-0.72) ${ }^{26}$ and worse overall survival when they received fluorouracil-based adjuvant chemotherapy (HR, 2.95; 95\% CI, 1.02-8.54). ${ }^{27}$ However, these approaches have limitations because most of the studies regarding MSI were retrospective and only the role of fluorouracil-based regimens was evaluated.

In recent years, attention has increased on carcinogenesis signaling pathways and CSC markers as predictors of cancer prognosis, as well as targets for cancer prevention and treatment. In multi-step carcinogenesis, the signaling pathway represents the overall process of carcinogenesis and tumor progression, and provides the basis for the genetic diversity of individual cancers. ${ }^{1}$ In addition, CSCs, which constitute only a small fraction of the tumor, exhibit properties of clonogenicity, differentiation, tumor initiation, recurrence, and metastasis. ${ }^{28}$ In particular, CSCs are resistant to conventional chemotherapy because they have a slow cell cycle and intrinsic defense mechanisms. ${ }^{4}$ CD133, CD44, CD166, CD24, ALDH-1, LGR5, EpCAM, and EphB2 are considered typical CSC markers of CRC, ${ }^{1,29}$ and most are related to the $\mathrm{Wnt} / \beta$-catenin signaling pathway. Therefore, in addition to prognostic markers of CSC related to Wnt/ 
$\beta$-catenin, we attempted to find more precise prognostic markers by adding mTOR signaling, which could be a prognostic molecular signal similar to Wnt/ $\beta$-catenin.

Based on adjusted multivariate analysis, combinations of CSC markers and two major CRC signaling pathways were associated with poor survival; the expression of each CSC marker alone was not associated with cancer-specific survival. The expression of CD44 or CD166 when combined with the expression of pS6 showed significant associations with poor cancer-specific survival. Our results showed that combinations of specific markers for CSC and mTOR had better predictive power for long-term prognosis than previously known high-risk features of poor prognosis in stage II CRC. In particular, the combination of CD166 and pS6 had the best predictive power for cancer-specific survival.

The mTOR signaling pathway is also a key dysregulated pathway in carcinogenesis that facilitates tumor invasion by modulating tumor metabolism, autophagy, cellular transformation, tumor progression, cell survival, and chemotherapy resistance. ${ }^{30,31}$ mTOR signals can be activated through the ERK/ MAPK and PI3K/AKT pathways induced by receptor tyrosine kinases, including EGFR and insulin receptor. ${ }^{31}$ In addition, a relationship between the EGFR/RAS/ERK/MAPK or PI3K/AKT pathways and CSCs has been reported in CRC. ${ }^{32-34}$ Therefore, the combination of CSC markers and active mTOR signals could suggest more aggressive tumor characteristics with metastasis and resistance to chemotherapy via synergic interactions.

Regarding liver metastasis, CD44 expression has been reported to be associated with increased risk of liver metastasis, ${ }^{4,32}$ although whether CD44 alone is sufficient is unclear. Bellizzi, et al. ${ }^{35}$ found the primary colon cancer compartment had a higher burden of CD133-positive cells and a lower burden of CD44positive cells than the metastatic compartment. In addition, all samples from metastatic patients showed a $\mathrm{CD}_{133^{+}} / \mathrm{CD}_{4} 4^{+}$phenotype, and samples from non-metastatic patients had a higher prevalence of the $\mathrm{CD} 133^{+} / \mathrm{CD}_{4}{ }^{-}$phenotype. Based on these findings, the authors emphasized the importance of co-expression of both markers in liver metastasis, suggesting the roles of CD133 in tumor growth and CD44 in tumor metastasis. In another study, $\beta$-catenin, a key component of Wnt signaling, was reported to be a liver metastasis predictor based on results showing significant accumulation of $\beta$-catenin at the invasive front and in vessels of samples from patients with liver metastasis, compared to patients without liver metastasis. ${ }^{36}$ In addition, the expression of CD44 and CD166 as CSC markers showed an overlap in tumor populations, and co-expression of both markers highlighted a select CSC population with more prominent characteristics of CSCs. ${ }^{37-39}$ Moreover, Wnt signaling is a major pathway involved in proliferation and maintenance of stem cells in normal and cancers, and CD44 is one of the targets of Wnt signaling. ${ }^{1}$ Therefore, the finding of combined CD44/ $\mathrm{CD} 166 / \beta$-catenin expression in the present study could be the most significant predictive marker associated with liver metas- tasis in stage II CRC.

In conclusion, specific combinations of CSC markers and an mTOR signal marker were independently associated with poor prognosis in stage II CRC. These combinations were also found to have better predictive power than previously described high-risk features or CSC markers alone. Thus, evaluation of these markers could be useful for selecting patients who will require more aggressive adjuvant chemotherapy or target-specific adjunctive treatments. Further clinical data from largescale studies and prospective trials are needed to confirm these findings.

\section{ACKNOWLEDGEMENTS}

This research was supported by the Basic Science Research Program through the National Research Foundation of Korea funded by the Ministry of Education (2013R1A1A2010733); the Korea Health Technology R\&D Project through the Korea Health Industry Development Institute funded by the Ministry of Health \& Welfare (HI14C1324); a faculty research grant of Yonsei University College of Medicine (6-2018-0059), Republic of Korea.

\section{AUTHOR CONTRIBUTIONS}

Conceptualization: Tae Il Kim and Jae Jun Park. Data curation: Ji Young Chang and Jae Hyun Kim. Formal analysis: Ji Young Chang. Funding acquisition: Tae Il Kim and Jae Jun Park. Investigation: Ji Young Chang, Jae Hyun Kim, Joyeon Kang, Yehyun Park, and Soo Jung Park. Methodology: Ji Young Chang, Jae Hyun Kim, Joyeon Kang, Hoguen Kim, and Tae Il Kim. Project administration: Tae Il Kim. Resources: Tae Il Kim, Jae Jun Park, and Hoguen Kim. Software: Ji Young Chang and Jae Hyun Kim. Supervision: Tae Il Kim and Jae Jun Park. Validation: Ji Young Chang, Jae Hee Cheon, Won Ho Kim, Tae Il Kim, and Jae Jun Park. Visualization: Ji Young Chang. Writingroriginal draft: Ji Young Chang. Writing_rreview \& editing: Ji Young Chang. Approval of final manuscript: all authors.

\section{ORCID iDs}

$\begin{array}{ll}\text { Ji Young Chang } & \text { https://orcid.org/0000-0002-7951-456X } \\ \text { Jae Hyun Kim } & \text { https://orcid.org/0000-0002-4272-8003 } \\ \text { Joyeon Kang } & \text { https://orcid.org/0000-0002-0256-7727 } \\ \text { Yehyun Park } & \text { https://orcid.org/0000-0001-8811-0631 } \\ \text { Soo Jung Park } & \text { https://orcid.org/0000-0003-0699-6809 } \\ \text { Jae Hee Cheon } & \text { https://orcid.org/0000-0002-2282-8904 } \\ \text { Won Ho Kim } & \text { https://orcid.org/0000-0002-5682-9972 } \\ \text { Hoguen Kim } & \text { https://orcid.org/0000-0002-7444-2771 } \\ \text { Jae Jun Park } & \text { https://orcid.org/0000-0001-9974-1658 } \\ \text { Tae Il Kim } & \text { https://orcid.org/0000-0003-4807-890X }\end{array}$

\section{REFERENCES}

1. Fedyanin M, Anna P, Elizaveta P, Sergei T. Role of stem cells in colorectal cancer progression and prognostic and predictive characteristics of stem cell markers in colorectal cancer. Curr Stem Cell Res Ther 2017;12:19-30. 
2. Reya T, Morrison SJ, Clarke MF, Weissman IL. Stem cells, cancer, and cancer stem cells. Nature 2001;414:105-11.

3. Lugli A, Iezzi G, Hostettler I, Muraro MG, Mele V, Tornillo L, et al. Prognostic impact of the expression of putative cancer stem cell markers CD133, CD166, CD44s, EpCAM, and ALDH1 in colorectal cancer. Br J Cancer 2010;103:382-90.

4. Jing F, Kim HJ, Kim CH, Kim YJ, Lee JH, Kim HR. Colon cancer stem cell markers CD44 and CD133 in patients with colorectal cancer and synchronous hepatic metastases. Int J Oncol 2015; 46:1582-8.

5. Horst D, Kriegl L, Engel J, Kirchner T, Jung A. Prognostic significance of the cancer stem cell markers CD133, CD44, and CD166 in colorectal cancer. Cancer Invest 2009;27:844-50.

6. Batlle E, Bacani J, Begthel H, Jonkheer S, Gregorieff A, van de Born M, et al. EphB receptor activity suppresses colorectal cancer progression. Nature 2005;435:1126-30.

7. Pitule P, Cedikova M, Daum O, Vojtisek J, Vycital O, Hosek P, et al. Immunohistochemical detection of cancer stem cell related markers CD44 and CD133 in metastatic colorectal cancer patients. Biomed Res Int 2014;2014:432139.

8. Shimokawa M, Ohta Y, Nishikori S, Matano M, Takano A, Fujii M, et al. Visualization and targeting of LGR5+ human colon cancer stem cells. Nature 2017;545:187-92.

9. de Sousa e Melo F, Kurtova AV, Harnoss JM, Kljavin N, Hoeck JD, Hung J, et al. A distinct role for Lgr5+ stem cells in primary and metastatic colon cancer. Nature 2017;543:676-80.

10. Logan CY, Nusse R. The Wnt signaling pathway in development and disease. Annu Rev Cell Dev Biol 2004;20:781-810.

11. Korinek V, Barker N, Morin PJ, van Wichen D, de Weger R, Kinzler KW, et al. Constitutive transcriptional activation by a beta-cateninTcf complex in APC-/- colon carcinoma. Science 1997;275:1784-7.

12. Morin PJ, Sparks AB, Korinek V, Barker N, Clevers H, Vogelstein B, et al. Activation of beta-catenin-Tcf signaling in colon cancer by mutations in beta-catenin or APC. Science 1997;275:1787-90.

13. Hong SN. Genetic and epigenetic alterations of colorectal cancer. Intest Res 2018;16:327-37.

14. Francipane MG, Lagasse E. mTOR pathway in colorectal cancer: an update. Oncotarget 2014;5:49-66.

15. Wullschleger S, Loewith R, Hall MN. TOR signaling in growth and metabolism. Cell 2006;124:471-84.

16. Zhang YJ, Dai Q, Sun DF, Xiong H, Tian XQ, Gao FH, et al. mTOR signaling pathway is a target for the treatment of colorectal cancer. Ann Surg Oncol 2009;16:2617-28.

17. Prodromidis G, Nikitakis NG, Sklavounou A. Immunohistochemical analysis of the activation status of the Akt/mTOR/pS6 signaling pathway in oral lichen planus. Int J Dent 2013;2013:743456.

18. Tanwar PS, Mohapatra G, Chiang S, Engler DA, Zhang L, KanekoTarui T, et al. Loss of LKB1 and PTEN tumor suppressor genes in the ovarian surface epithelium induces papillary serous ovarian cancer. Carcinogenesis 2014;35:546-53.

19. Lugli A, Spichtin H, Maurer R, Mirlacher M, Kiefer J, Huusko P, et al. EphB2 expression across 138 human tumor types in a tissue microarray: high levels of expression in gastrointestinal cancers. Clin Cancer Res 2005;11:6450-8.

20. Fleming M, Ravula S, Tatishchev SF, Wang HL. Colorectal carcinoma: pathologic aspects. J Gastrointest Oncol 2012;3:153-73.

21. Varghese A. Chemotherapy for stage II colon cancer. Clin Colon Rectal Surg 2015;28:256-61.

22. Chang JY, Shim KN, Tae CH, Lee KE, Lee J, Lee KH, et al. Comparison of clinical outcomes after endoscopic submucosal dissection and surgery in the treatment of early gastric cancer: a single-insti- tute study. Medicine (Baltimore) 2017;96:e7210.

23. Benson AB 3rd, Schrag D, Somerfield MR, Cohen AM, Figueredo AT, Flynn PJ, et al. American Society of Clinical Oncology recommendations on adjuvant chemotherapy for stage II colon cancer. J Clin Oncol 2004;22:3408-19.

24. Labianca R, Nordlinger B, Beretta GD, Mosconi S, Mandalà M, Cervantes A, et al. Early colon cancer: ESMO Clinical Practice Guidelines for diagnosis, treatment and follow-up. Ann Oncol 2013;24 Suppl 6:vi64-72.

25. O'Connor ES, Greenblatt DY, LoConte NK, Gangnon RE, Liou JI, Heise CP, et al. Adjuvant chemotherapy for stage II colon cancer with poor prognostic features. J Clin Oncol 2011;29:3381-8.

26. Ribic CM, Sargent DJ, Moore MJ, Thibodeau SN, French AJ, Goldberg RM, et al. Tumor microsatellite-instability status as a predictor of benefit from fluorouracil-based adjuvant chemotherapy for colon cancer. N Engl J Med 2003;349:247-57.

27. Sargent DJ, Marsoni S, Monges G, Thibodeau SN, Labianca R, Hamilton SR, et al. Defective mismatch repair as a predictive marker for lack of efficacy of fluorouracil-based adjuvant therapy in colon cancer. J Clin Oncol 2010;28:3219-26.

28. Medema JP. Targeting the colorectal cancer stem cell. N Engl J Med 2017;377:888-90.

29. Merlos-Suárez A, Barriga FM, Jung P, Iglesias M, Céspedes MV, Rossell D, et al. The intestinal stem cell signature identifies colorectal cancer stem cells and predicts disease relapse. Cell Stem Cell 2011;8:511-24.

30. Fujishita T, Aoki M, Taketo MM. JNK signaling promotes intestinal tumorigenesis through activation of mTOR complex 1 in $\operatorname{Apc}(\Delta 716)$ mice. Gastroenterology 2011;140:1556-63.e6.

31. Bahrami A, Khazaei M, Hasanzadeh M, ShahidSales S, Joudi Mashhad M, Farazestanian M, et al. Therapeutic potential of targeting PI3K/AKT pathway in treatment of colorectal cancer: rational and progress. J Cell Biochem 2018;119:2460-9.

32. Ribeiro KB, da Silva Zanetti J, Ribeiro-Silva A, Rapatoni L, de Oliveira HF, da Cunha Tirapelli DP, et al. KRAS mutation associated with CD44/CD166 immunoexpression as predictors of worse outcome in metastatic colon cancer. Cancer Biomark 2016;16: 513-21.

33. Patel BB, Yu Y, Du J, Levi E, Phillip PA, Majumdar AP. Age-related increase in colorectal cancer stem cells in macroscopically normal mucosa of patients with adenomas: a risk factor for colon cancer. Biochem Biophys Res Commun 2009;378:344-7.

34. Moon BS, Jeong WJ, Park J, Kim TI, Min do S, Choi KY. Role of oncogenic K-Ras in cancer stem cell activation by aberrant Wnt/ $\beta$-catenin signaling. J Natl Cancer Inst 2014;106:djt373.

35. Bellizzi A, Sebastian S, Ceglia P, Centonze M, Divella R, Manzillo $\mathrm{EF}$, et al. Co-expression of CD133(+)/CD44(+) in human colon cancer and liver metastasis. J Cell Physiol 2013;228:408-15.

36. Suzuki H, Masuda N, Shimura T, Araki K, Kobayashi T, Tsutsumi S, et al. Nuclear beta-catenin expression at the invasive front and in the vessels predicts liver metastasis in colorectal carcinoma. Anticancer Res 2008;28:1821-30.

37. Dalerba P, Dylla SJ, Park IK, Liu R, Wang X, Cho RW, et al. Phenotypic characterization of human colorectal cancer stem cells. Proc Natl Acad Sci U S A 2007;104:10158-63.

38. Su YJ, Lai HM, Chang YW, Chen GY, Lee JL. Direct reprogramming of stem cell properties in colon cancer cells by CD44. EMBO J 2011;30:3186-99.

39. Pandurangan AK. Potential targets for prevention of colorectal cancer: a focus on PI3K/Akt/mTOR and Wnt pathways. Asian Pac J Cancer Prev 2013;14:2201-5. 